\title{
Estudo Analítico da Técnica de Glicerinação Empregada Para Conservação de Peças Anatômicas - Experiência da Disciplina de Anatomia Humana do Departamento de Morfologia do UniFOA
}

\section{Study of glycerination method used for conservation of anatomic parts - Experi- ence of Anatomy discipline of the Morphology Department/UniFOA.}

\section{Artigo \\ Original}

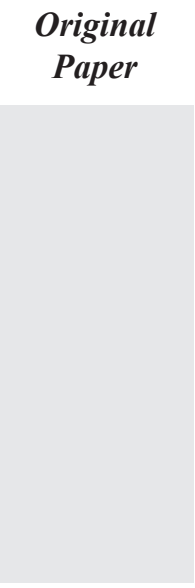

Submetido

em: 17/12/07

\section{Revisado}

em: 01/03/08

Aceito para

Publicação

em: 08/03/08

\author{
Evandro M. e Silva ${ }^{1}$ \\ Gilvando Dias ${ }^{1}$ \\ Mauro Tavares ${ }^{1}$ \\ Tatiana Marques ${ }^{1}$ \\ José Marciano Furtado ${ }^{2}$
}

Palavras-chaves:

Cadáver

Anatomia

Glicerina

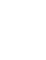




\section{Introdução}

Os egípcios, há mais de 5000 anos, já se preocupavam com a conservação dos corpos. Questões de vida e de morte, para os egípcios, eram reservadas apenas ao coração. No músculo que bombeia sangue para todos os outros órgãos do corpo ficaria a sede da razão e da emoção, da memória e da sabedoria, da alma e do amor. O coração era o único órgão preservado nos corpos mumificados dos faraós, que passavam parte da vida obsessivamente ocupados com a construção de monumentos para abrigar seu cadáver, além da comida, de jóias, de parentes e animais de estimação que lhes deviam acompanhar na viagem em direção à imortalidade. A civilização egípcia, que surgiu por volta de 3100 a.C., acreditava que depois da morte seria possível comer, beber e apreciar o odor dos incensos. Por isso, qualquer dano ao corpo e à sua essência - o coração - era considerado uma maldição terrível para a chegada da "segunda morte", segundo descreve o papiro Ebers, uma espécie de enciclopédia médica usada durante a $18^{\mathrm{a}}$ dinastia do Egito, a mesma do faraó Tutankhamon. A preparação da múmia chegava a durar 70 dias e, durante pelo menos metade desse tempo, o corpo ficava coberto por um mineral chamado natrão, sal que desidrata os tecidos, fazendo com que, pela falta d'água, nem mesmo as bactérias e os fungos responsáveis pela decomposição consigam sobreviver. Para proteger a pele, os corpos eram então envoltos por ataduras feitas de linho, com orações desenhadas sobre o mesmo tecido. A preocupação pela conservação de corpos humanos continuou, pois o ser humano se nega a, ao final de sua vida, ser convertido simplesmente em nada. Muitas foram as técnicas e formulas químicas empregadas ao longo do tempo, que, se bem conseguiram alguns resultados parciais, não resolveram satisfatoriamente o problema da conservação dos corpos. Andrés Vesalius (1514-1564), anatomista flamenco, foi um dos primeiros em sistematizar a dissecção anatômica como método de ensino, o que lhe valeu o título de Pai da Anatomia. A partir deste momento passou a se pensar na conservação de cadáveres e peças anatômicas para finalidades didáticas e acadêmicas. No século XVIII as técnicas de conservação de corpos humanos experimentaram importante desenvolvimento devido principalmente aos seguintes inves- tigadores: Guilhermo Hunter (1718-1783), que utilizava o álcool como meio de fixação e conservação. Pierrento Dionis empregava o ácido tânico para se evitar o criscimento de fungos. Froncois Chaussier (1742-1828), empregou o bicloreto de mercúrio para evitar a putrefação e favorecer a mumificação. Johann Jacob Ritter (1714-1784), utilizou o arsênico. Karl Wilhelm Sheele (1742-1786) (Fig. 1), um farmacêutico sueco, foi quem descobriu a glicerina. Na época, ele a batizou de "o doce princípio das gorduras". Coube ao anatomista italiano Carlo Giacomini (1840-1898), a primeira utilização da glicerina para preservar corpos, cuja técnica ganhou o seu nome (Fig. 2). Posteriormente, 1868, August Wilhem V. Hoffmann (1818-1892), químico alemão, descobriu e passou a utilizar o formol como substância para conservar cadáveres.

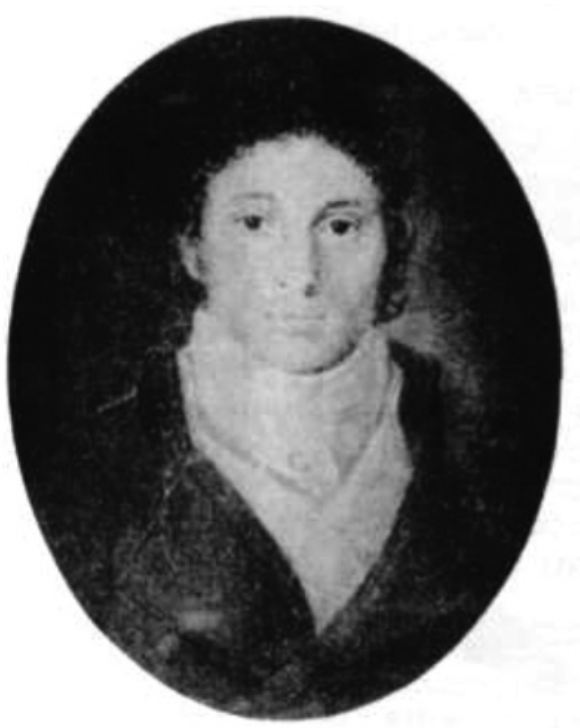

Fig. 1 - Fotografia de Karl Wilhelm Scheele

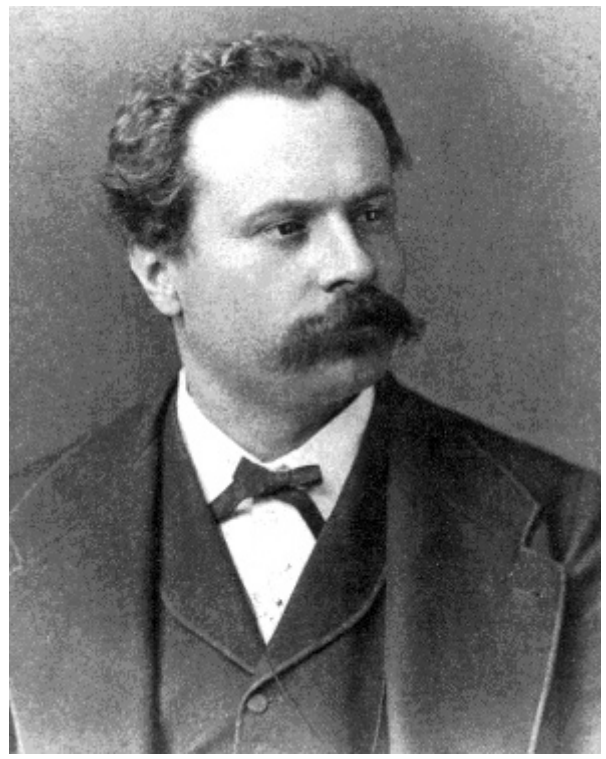

Fig. 2 - Fotografia de Carlo Giacomini

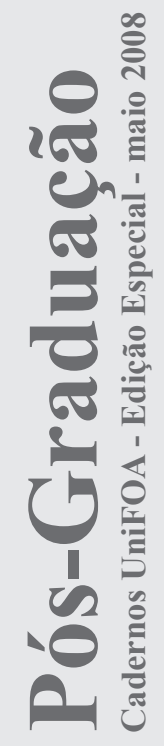


O termo Glicerina ( ${ }^{\circ}$ CAS: 56-815) refere-se ao produto na forma comercial do glicerol, com pureza acima de $95 \%$. Este último é um composto orgânico pertencente à função álcool. É líquido à temperatura ambiente $\left(25^{\circ} \mathrm{C}\right)$, higroscópico, inodoro, viscoso e de sabor adocicado. O nome origina-se da palavra grega glykos ( $ү \lambda$ uKóৎ), que significa doce.

\section{Aspéctos Técnicos}

No que se refere à técnica de glicerinação de cadáveres, ou peças anatômicas (Fig. 3), os seguintes passos são fundamentais:

1. Formolização da peça anatômica com formol à $10 \%$.

2. Preparo da peça mediante dissecção anatômica.

3. Glicerinação, que deverá envolver três etapas:

- Desidratação

- Clareamento

- Impregnação da glicerina a 98\%

- Escoamento

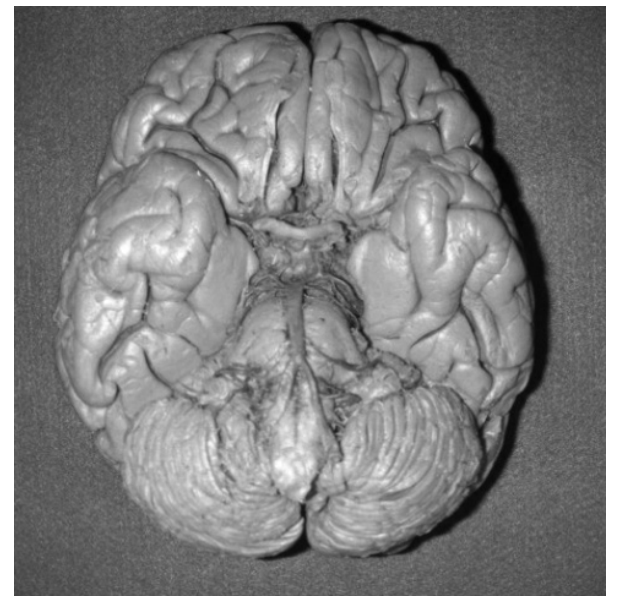

Fig. 3 - Fotografia de um cérebro humano glicerinado.

\section{Discussão}

Vários são os fatores que devem ser levados em consideração quando iremos escolher a melhor forma de conservação de peças anatômicas. Os custos, a toxidade, a técnica, o manuseio das peças após o preparo, a necessidade de manutenção, a manutenção da morfologia e coloração os mais próximos possíveis do estado real, o odor são os principais fatores a serem avaliados. No que se refere à custos, os valores são muito próximos, pois o preço do litro de formol, peróxido de hidrogênio e glicerina, estão, respectivamente, aproximadamente, em R $\$ 5,10, \mathrm{R} \$ 6,85$ e
$\mathrm{R} \$ 7,00$. Devemos lembrar que à medida que passamos a utilizar a glicerina como forma de conservação dos corpos, o formol não estará totalmente abandonado, pois, inicialmente, as peças deverão ser formolizadas. Indiscutivelmente o formol é a substância mais tóxica, inclusive com vários trabalhos publicados sobe a capacidade carcinogênica do mesmo. Em relação à técnica, o formol se mostra mais prático, pois basta a introdução da mesma no cadáver via intravascular e depois a manutenção submersa das peças em concentrações em torno de 5\%. A glicerina exige maiores cuidados, como por exemplo, a peça deverá estar muita bem dissecada e a mesma deverá ficar submersa totalmente por, aproximadamente, 7 dias; quando usamos pressão positiva este tempo pode cair pela metade. As peças glicerinadas se mostram muito mais fáceis de serem manuseadas, quando comparadas as peças formolizadas, pois além da menor intensidade do cheiro, o peso é mais leve. As mesmas não ficam encharcadas de líquido, o que,na maioria delas, leva a duplicar o seu peso. Isso pode não ser um fator muito importante para peças pequenas. Contudo, quando utilizamos cadáveres inteiros, e os precisamos deslocá-los, é que sentimos a diferença. A glicerina tem um ponto muito forte à seu favor, que é não escurecer muito as peças. Neste ponto é que entra o peróxido de hidrogênio, pois é esta substância que misturada à glicerina, tornará a peça muito mais clara que as peças formolizadas. Esta clareza se traduz em cores mais próximas do real, o que facilitará o estudo prático da anatomia porque o aluno correlacionará mais facilmente a peça anatômica ao atlas. A morfologia é outro ponto importante que a glicerina mantém sob a forma original.

\section{Conclusão}

Com este nosso breve estudo pode-se concluir que a glicerinação (glicerina mais peróxido de hidrogênio) é uma técnica eficiente para a conservação de peças anatômicas, de custos próximos à formalização, de resultados estéticos e morfológicos melhores, inodora, e de fácil manuseio tanto pelos professores quanto pelos alunos. 
ANDERSON, B.G. \& ANDERSON, W.D.

Renal muscultures of the trout demonstrated by SEM, compared with canine glomerular vessels. Am.J.Anat., 45: 443-488, 1976.

BICKLEY, H.C. et al. An improved method for the preservation of teaching specimens. Arch.Pathol.Lab.Med., 105: 674-676, 1981.

BUGGE, J. A standardized plastic injections technique for anatomical purposes. Acta Anat., 54: 177-192, 1963.

GIACOMINI, C. Instituo e museo di storia della sienza. Disponible em http://brunelleschi.imss.fi.it/nobel/ileviatorino.html. Acessado em 11/11/2007.

JUNGERMANN, E; SONNTAG, N. O. V. Glycerine: a key cosmetic ingredient. New York: Marcel Dekker, 460 p. 1991.

MERODIO, J.N. Método para conservar pulmones insuflados y desecados. Arch.Mex. Anat., 8 (29): 17-19, 1969.

RODRIGUES, H. Técnicas anatômicas. Ministério da Educação e Cultura, Juiz de Fora, MG 1973.

SAEED M, RUFAI AA, ELSAYED SE. Mummification to plastination. Revisited. Saudi Med J 2001 Nov;22(11):956-9.

TOMPSETT, D.H. Anatomical techniques. Edinburg and London, 1970.

TORRES, J. R. P, MOLINARI, S.L. Conservação de peças anatômicas em glicerina. Arq. Apadec, 8(supl.): Mai, 2004.

Informações bibliográficas:

Conforme a NBR 6023:2002 da Associação Brasileira de Normas Técnicas (ABNT), este texto científico publicado em periódico eletrônico deve ser citado da seguinte forma:

SILVA, E. M.; SOUZA FILHO, G. D.; SOUZA, M. C. T.; MARQUES, T.; FURTADO, J. M..

Estudo Analítico da Técnica de Glicerinação Empregada Para Conservação de Peças Anatômicas - Experiência da Disciplina de Anatomia Humana do Departamento de Morfologia do UniFOA.

Cadernos UniFOA, Volta Redonda, ano 3, Edição Especial, maio. 2008. Disponível em: <http:// www.unifoa.edu.br/pesquisa/caderno/especiais/pos-graduacao/01/66.pdf> 